\title{
A study of the labor process from a technology transformation perspective: the case of internet virtual teams
}

\author{
Meng Liang*
}

\author{
*Correspondence: \\ pkulemon@163.com \\ China Agricultural University, \\ Beijing, China
}

\begin{abstract}
This article presents an empirical study of the labor process of internet virtual teams. It argues that organizations with a "horizontally virtual and vertically real" structure face a dilemma in the virtual team labor process. While a culture of engineers, which embodies equality, liberty, and cooperation, is the cultural basis of the virtual team, management is bureaucratic, emphasizing individual interests and hierarchical features. The coexistence of the two leads to cooperation and division of labor in virtual teams. Essentially, this is a compromising institutional arrangement adopted by corporations to triangulate technology culture and managerial control to obtain surplus value. Based on the preceding discussion, this paper ends by proposing a new theoretical framework for studying the labor process under the technological conditions of the internet.
\end{abstract}

Keywords: Labor process, Technological transformation, Internet, Virtual team, Cultural capital

\section{Introduction}

For Karl Marx, the essence of social analysis lies in production labor. In considering the development of Marx's theory, it is evident that he perceives two types of relationships in production: the relationship between humans and nature and the interrelationship among humans. The latter determines the nature of a whole society. Therefore, production labor has always been the core focus in Marxian analyses. Labor process theory and related research have also developed along these lines.

As the intrinsic mode of production of human society gradually shifts from mechanical production to information production, researchers have coined concepts such as industrial society, postindustrial society, and consumer society to capture the change and characteristics of each stage. The rapid development of the information industry and internet technologies since the 1990s led Castells (2009: 33) to propose the concept of a "network society." The theoretical core still focuses on the issue of labor. Subsequently, researchers who respond to Castells' theory also focus on the labor issue of a network party material in this article are included in the article's Creative Commons licence, unless indicated otherwise in a credit line to the material. If material is not included in the article's Creative Commons licence and your intended use is not permitted by statutory regulation or exceeds the permitted use, you will need to obtain permission directly from the copyright holder. To view a copy of this licence, visit http:// creativecommons.org/licenses/by/4.0/. 
society from the perspectives of structural inequality and labor production (Qiu 2009; Wang 2011).

While intellectual continuity is beneficial for discovering the nature of society, the fact that the existing analytical framework is built on industrial production exposes researchers to the risk of overlooking critical factors of production labor in the network society if they use it uncritically. Specifically, as an emerging technology industry with the aim of "chang[ing] the world with technology," the internet is transforming everyone's work and life worldwide. However, how do we "change the world with technology?" How can we understand labor and the internet industry and thereby understanding the network society? We still need answers to these questions. This article returns to the initial goal of the labor process research and to the core of production to investigate modes of production, the labor process, the institution of production, and ideology. With a review of relevant theories and an analysis of a case study, this article pushes for a preliminary understanding of the network society from the perspective of technology and labor relations.

\section{Technology and ideology in labor process theory}

\section{The developmental path of the theory}

Labor process theory originates from Marx's research and focuses on analyzing the management and control of the capital. Marx maintains that the only goal of production for capitalists is to obtain surplus value. The production of surplus value requires the transformation of labor power into actual labor (Marx 2004: 207). The process of transformation, however, is rife with uncertainty. To suppress uncertainty and ensure the generation of surplus value, capital adopts a multimanagement and multicontrol strategy. As such, Marx's research on the labor process focuses on management and control by capital and resistance by workers. Subsequent researchers developed the theory to varying extents, but the core of their discussion remains the same.

After Marx, scholars such as Harry Braverman and Michael Burawoy contributed to the development of labor process theory. Generally, their analyses on the management and control of capital follow two main paths.

The first is technological transformation. Braverman argues that the distinctive indicator of the transformation of production from liberal capitalism into monopolizing capitalism is the introduction of mechanical production technology. On this basis, the capital's controlling strategy changes tremendously (Braverman 1978: 152). The main indicators are the decoupling of concepts and implementation in the labor process and the use of Tayler's scientific management. Prior to that, although a certain level of supervision and management already existed in production, workers still held the absolute majority of knowledge and control power, whereas capital exercises control mainly by supervising the output of labor. Monopolizing capitalism, however, extends capitalist control of the labor process through scientific management that develops from the spread of large-scale mechanical production. This is accomplished in three ways. First, technology and the labor process are decoupled. The production process is simplified and mechanized so that production no longer relies on workers' skills but requires only simple physical labor-that is, "the labor process should not rely on craft, tradition, and worker knowledge" (Braverman 1978: 104). Second, concepts and implementation are decoupled. Taylor proposes to "remove all brainwork from the factory into the planning 
or designing departments" (Braverman 1978: 104). The study of the working process and the interpretation of its output must be undertaken by capital, and the workers only receive and follow simple operational instructions without much thinking. Based on these two step-ways, the third is "using the monopoly on knowledge to control every step in the labor process and its implementation" (Braverman 1978: 110). Direct control by the capital of the labor process is thus achieved. Workers are deskilled and turned into merely part of the production machine.

Other contemporary scholars, however, have put forth different ideas. Friedman (1977: 77-78, 106-108) points out the limitation of the "concept and implementation" strategy: because of the possibility of workers' agency and resistance, scientific management as the sole controlling strategy of capital is difficult to sustain. Instead, Friedman proposes a polarizing management strategy based on "direct control" and "responsible autonomy." Direct control refers to the implementation of scientific management, with the close control and supervision of the labor process, making workers part of the machine. Responsible autonomy, to a certain extent, defers the right of control of the labor process to workers, giving them some agency and decision-making ability. Friedman emphasizes that these two management strategies are not contradictory, but that management should alternate them and even create transitional strategies between these two extremes.

Edwards (1979: 110-131) agrees with Braverman's assertion about the transformation of capitalist controlling strategies following the spread of mechanical production technology. However, he attributes it to the expansion of corporation scope as a result of mechanical production, which makes simple and direct supervision strategies inadequate. Therefore, structural control that is more suitable for large-scale mechanical production modes, including technological control and bureaucratic control, embeds control into the production technology and rhythm of the entire factory as well as into the organizational structure of the factory. This indicates Edwards' belief that structural control is a management strategy beyond simple controlling methods such as scientific management. This controlling strategy considers not only the labor process itself but also extends control to the entire organizational structure and technological design. It is, therefore, a stronger controlling method.

The three scholars referenced above all discuss capitalist control over the challenges brought about by the technological transformation of large-scale mechanical production. Here, technology is a critical dimension that brings not only the benefits of increased productivity and expanded corporate scope but also challenges as workers become stronger in both skill and number. It becomes not only the reason for capital to change its controlling method but also part of capitalist control. Technology, therefore, becomes the key in the game between capital and labor in development, with the capital being the major beneficiary in the industrial production stage.

The second main path is the discussion of ideology in production. Burawoy maintains that although the multiple capitalist controlling strategies that follow the technology transformation perspective could produce expected management outcomes, workers, after all, have agency and self-realization and, under such strict control, will inevitably resist. However, in Burawoy's ethnographic work, he did not observe intense resistance. On the contrary, he found himself caught in "the game of making out." He then realized 
the inadequacy of analyzing labor processes and capital control through technological transformation and controlling strategies. We must also pay attention to the subjective aspects of production-that is ideology. In Burawoy's research, ideology in production includes the ideology-molding mechanisms of capital and the ideology that workers form in the process - that is, the "consent" to capitalist exploitation and their voluntary and willing participation in their own exploitation. Thus, the "consent" of workers is shaped by capital through microlevel labor processes and macrolevel structural arrangements. It is a form of "manufactured consent" (Burawoy 2005: 217-224).

Some scholars have claimed that the most important contribution that Burawoy has made to labor process theory is his highlighting of workers' agency, which corrects the bias of the theory to place too much focus on work and too little on workers (You 2006; Wen and Zhou 2007). This is, of course, a meaningful argument, but Burawoy's research extends further than that. Another critical point that he has made about worker agency is how capital shapes workers' ideology. On the one hand, this shaping mechanism reminds us of the existence and importance of worker agency. On the other hand, it also reveals how worker agency is shaped and alienated in industrial production in monopolizing capitalism. Therefore, the research pays critical attention to the formation and modus operati of this ideology-shaping mechanism - that is, to establish an understanding of the labor process and laborers under the macroframework of the production politics.

Generally, studies that follow the technology path emphasize the development of production technology and the objective aspects of capital control that result from it, including strategies such as direct control, responsible autonomy, skill control, and bureaucratic control. Even workers themselves are objectified through deskilling. In contrast, studies that follow the ideology path emphasize workers' agency in the labor process and the mechanism by which capital shapes ideology. That is, the subjective aspects of capital control. In the existing theoretical tradition, technology and ideology stand as two independent, unintegrated factors. The network society, with the transformation of internet technology (especially the cultural features of technology), has already begun to challenge conventional wisdom. When technology acquires a cultural dimension, or when culture is embedded in technology, how do we understand the relationship between the two?

\section{Relevant empirical research}

The existing empirical research on internet labor still follows the traditional analytical framework of labor process theory, formulated under industrial production. Some scholars follow Braverman and Friedman to discuss how capital in internet companies makes control strategies more flexible. For example, Australian scholar Barrett (2004) shows how the software company Webboyz controls engineers by giving them autonomy regarding time and projects while reverting to systems of direct control and supervision with urgent projects. Based on this unfixed management style, Barrett proposes a multilayered management strategy. Direct control and responsible autonomy are two ways managers control software engineers, but they do not stand against each other. Instead, management uses them alternately or simultaneously based on comprehensive structural, environmental, and human factors. 
Other scholars depart from Burawoy's ideology path, focusing on the issue of culture in internet labor. In his book Engineering Culture, Kunda demonstrates how the elite IT firm, in which he works while conducting his ethnography, exercises an engineer culture that promotes concepts such as open-mindedness and flexibility. Kunda refers to that new management strategy as one of "normative control" (Kunda 2006: 11), which "attempt[s] to elicit and direct the required efforts of members by controlling the underlying experiences, thoughts, and feelings that guide their actions" (2006: 11). This is a new strategy by which capital controls knowledge workers from a cultural and emotional perspective. Capital promotes coherence between the interests of individual employees and the interests of the firm, bottom-up decision-making, and the weakening of hierarchy. A series of rituals and institutional arrangements reinforce it. The concept of normative control has a certain influence on subsequent research (Upadhya 2008). Scholars further propose that as the concept and implementation of laborers are dissected by capital in traditional industries, in the production of knowledge, the emotion of laborers is also controlled by capital through strategies such as normative control, thereby influencing laborers' self-identity and organizational committment (Thompson and Chris 1998).

All the aforementioned studies are built on a solid empirical foundation. The first perspective views the controlling strategy of internet labor as integration and extension of industrial production. The second perspective calls attention to the issue of ideology in the labor process-engineer culture-but it also situates such culture as being rooted in the controlling strategy of capital and unrelated to laborers. To summarize, the existing empirical research overlooks the difference between internet technology and traditional industrial technology. Although both paths that depart from labor process theory have noted changes in internet knowledge labor and its capital control, neither has conducted an in-depth discussion on changes in the essence of the internet labor process because of inadequacies in the explanatory framework.

\section{Technology transformation: the rise of internet technology, tech culture, and its influence on labor}

Currently, it is agreed that internet technology emerged from two mid-twentieth-century projects. One is the Advanced Research Project Agency Net (ARPANET) project, operated by the Advanced Research Projects Agency funded by the U.S. Department of Defense. Despite its military background, the ARPANET primarily focused on building an interactive communication network among scholars' computers. Another is the Bulletin Board System (BBS), which was started by civilian computer amateurs such as college students and professional computer engineers. Because of its military considerations, the ARPANET emphasized multicentralization and flexible design. The BBS built a platform for file transmission between individuals and promoted a culture where common users would use the internet by publicizing software, free use, and providing systemic revision suggestions. The open-source model movement of the Linux system further demonstrates the idea of an internet culture of equality, openness, and cooperation (Castells 2007: 2).

Regarding the generative mechanism of internet technology culture, Castells argues that the key is the organization created by this technology. Considering projects such as the ARPANET and the BBS, it is clear that the emergence and early development 
of internet technology are driven by individuals from large research institutes and colleges and early practitioners of computing technology. These social groups have a liberalist tradition that praises intellectual pursuit. Such cultural traits colored internet technology and practices (Castells 2007: 19). As such, internet technology differs from traditional technology in terms of form and ideology, which acquires significant characteristics of a culture of technology ${ }^{1}$ or tech culture. First, the internet tech culture exists prior to and is embedded in technology, and the rules and structure of technology are a reflection of technology. Second, the internet tech culture influences not only work but also the world (as in the vision that "technology changes the world"). From this perspective, it is not enough to focus only on the technology itself when we discuss internet technology. We also need to investigate the ideological layer of technology-that is, tech culture.

Since the late 20th century, the development of internet technology has happened primarily in the business sector, giving rise to internet corporatist culture (Castells 2007: 42). However, the original cultural traits of internet technology are partly retained. The pursuit of the vision that "technology changes the world" and the promotion of an open, equal, and free working culture are still shared characteristics of top internet firms around the globe. Certainly, as computers and the internet spread in all industries, work in other industries is also considerably influenced by them. Regarding the influence of tech culture, internet companies, which are the core sector of internet technology, are still the most representative. This is the reason this study chooses internet companies as its subjects of study.

In the backdrop of such a tech culture, how do internet companies construct the labor process? Considering the cases included in this article, tech culture and managerial control coexist in the internet labor process, simultaneously contradicting and cooperating with each other and driving the continuous rapid development of internet companies. Internet labor is a challenge to the traditional analytical framework of labor process theory. Internet technology and its culture are becoming an increasingly important influence in the labor process.

As such, an urgent challenge to labor study in the twenty-first-century network society-and, especially the issue of knowledge labor-is how to revise the existing framework so that we can focus not only on the objective transformation of technology but also on the changes in ideology in labor and the relationship between the two. An ongoing effort to explore this issue from both theoretical and empirical perspectives is needed. Based on these considerations, the present study chooses a typical elite internet company as the subject of fieldwork. We attempt to provide a portrait of internet labor and demonstrate evidence for theoretical discussion by examining its labor process.

\footnotetext{
${ }^{1}$ On the relationship between internet culture and ideology, Castells clarifies that the culture that he discusses is more concrete and practical than ideology and that, therefore, the two cannot be equated. This paper discusses the issue in the area of production. In the internet labor process, tech culture is an important source of ideology. On the one hand, laborers acquire cultural capital from the culture of technology (Bourdieu and Wacqant 2004: 212) and thereby a certain degree of autonomy. On the other hand, the firm's reshaping of laborers' technology culture and cultural capital gives rise to a labor ideology and generative mechanism unique to the internet labor process.
} 


\section{Double contradictions: the labor process of the internet Firm E}

Established in 2000 and going public in the U.S stock market in 2005, Firm E ${ }^{2}$ was one of the best among Chinese internet companies. The founder and Chief Executive Officer (CEO) of Firm $E$ is a technical expert in computer science with overseas education and work experience. As of 2014, the firm had over 30,000 employees in Beijing, Shanghai, Guangzhou, and other cities, with headquarters in Beijing. Like many other Chinese internet companies, Firm $\mathrm{E}$ has a delicate division of labor ${ }^{3}$ and a project-centered production mode.

To finish a project, laborers from all job categories must cooperate. In Firm E, this process is accomplished mainly through virtual teams. Laborers from different real teams and job categories carry out one project based on the technical division of labor and a non-hierarchical structure. Compared with the bureaucratic hierarchy in real teams, virtual teams comprise a relatively equal relation. In the organization, real teams are responsible for task assignment and performance evaluation while virtual teams drive production. Each mode has its emphasis, constituting a "horizontal-virtual and verticalreal" organizational structure.

The firm intentionally forms this structure to fuel knowledge production. However, it is difficult to avoid problems caused by the difference between real and virtual organizational practices. The fieldwork has found two major contradictions in the labor process. One is the ideological contradiction between engineer culture and bureaucracy. Another is the contradiction between the virtual team and the real team.

\section{The institutional foundation of virtual teams}

Establishing virtual teams inside Firm $\mathrm{E}$ is not isolated but related to a series of institutional and cultural arrangements. It is on the basis of relevant organizational institutions and culture that this ideal-typical mode of cooperation can function in practice. In Firm E, virtual teams are related to two main organizational features: engineer culture and bureaucratic performance management.

\section{Engineer culture}

Castells coined the term "a four-layer structure" to describe internet culture: "the techno-meritocratic culture, the hacker culture, the virtual communitarian culture, and the entrepreneurial culture" (Castells 2007: 38). Technical elite culture is the ultimate reflection of "a mission of world domination by the power of knowledge" (Castells 2007: 60). In Firm E, this mission is enlisted in its engineer culture.

The most direct demonstration of this mission is salary. Taking fresh college graduates as an example, the average salary of computer and internet engineers exceeds that of other occupations by $20 \%$. Computer and internet engineers often have the opportunity to obtain scarce hukou quotas. Furthermore, besides the common compensation

\footnotetext{
${ }^{2}$ The firm and interviewers are all anonymized.

${ }^{3}$ To be specific, the traditional broad categories of "software developer" or "engineer" in Firm E are divided into occupations such as FE, SA, RD, QA, PM, UE, UI, and OP. Each professional job category constitutes an independent department or system. For example, RD belongs to the R\&D system, PM to the production system, and UI to the user experience system. Each system is administratively independent. That is, each has its own performance evaluation and promotion assessment.
} 
that Firm E provides for all departments, the technology department has specific extra benefits, including the weekly provision of snacks and relaxation and exercise equipment such as foosball tables and table tennis tables. Management even organizes regular group online games during working time as a team-building activity.

Outside of work, Firm E organizes various technical competitions. The model-hacker innovation competition is a classic example. In this competition, technical employees form their own teams and meet at the competition spot. In $24 \mathrm{~h}$, they sacrifice sleep to bring a product idea to life. In the process, technical employees at lower levels of the firm have an opportunity to show their skills and creativity to the firm's leaders. Competitions of this kind give the firm a path to innovation, and they provide a perfect opportunity to exercise engineer culture.

In actual cooperation, engineers also enjoy certain privileges.

As I see it, the so-called engineer culture just means that the firm values engineers. Most directly, (engineers) have the highest salary. Their salary is about 20\% higher than that of PMs(Product Manager). The engineer culture is reflected in, as I said, the discourse of engineers. They have options. For example, when we design products, $R D$ (Research and Development engineer) doesn't just make what PMs design. If $R D$ don't think your product is good enough, they'll tell you what they want to make.

Generally, the engineer culture promoted by Firm $\mathrm{E}$ is a concrete reflection of the internet culture on core technical laborers. The difference, however, is that Firm E's engineer culture emphasizes the preference over and reliance on technical laborers. This has profound implications for cooperation in the labor process.

\section{Bureaucratic performance evaluation}

Internet firms often emphasize their flat organizational structure, taking pride in an internet culture of equality and democracy that reflects that structure. Consistent with what it advertises to the public, Firm E has only five levels-entry-level employees, managers, directors, Vice Presidents (VPs), and the CEO. However, on closer inspection, we find that each of the three middle levels is further divided. There are managers and senior managers, vice directors, directors, senior directors, VPs, senior VPs, and executive VPs. Under the disguise of a flat structure is a ten-level administrative hierarchy. Internet firms are still largely bureaucratic organizations. Performance management, a critical method for managerial control, is also organized through such a bureaucratic structure.

In internet firms, performance management is the main method of work evaluation. The firm breaks down its general goals, distributes responsibilities to individual laborers, and evaluates performance through quantitative and measurable indicators. The result of this process determines the reward, punishment, and career development of the laborer. Performance indicators are divided into two levels.

At the organization level, target setting and measurement use the balanced scorecard system. At its tenth anniversary, Firm E proposed a target to achieve 40 times its

${ }^{4}$ Interview of with Dewei Zhou, Project Manager of Firm E, August 21st, 2012. 
revenue in the next 10 years. This goal was broken down into mid-term strategies and relative strategic targets and then further into annual strategic targets and quantifiable annual working KPs and their key performance indicators (KPIs).

At the individual level, target setting is based on the well-known performance management measure of the KPI. KPs are the important tasks an employee must accomplish, the "focus of work that you should put the most attention and effort into." KPIs are "items and markers to measure the completion of KP." A common employee will have no more than 5 KPs, with each KP having no more than 3 KPIs. Presidents set their own annual KPIs based on the firm's annual goal. Leaders of Departments set their own KPIs based on KPIs of their corresponding VPs, and so on down the hierarchy until the KPIs are extended to entry-level employees. At every level, the manager's performance target is the sum of all performance targets of her subordinates. In addition to KPIs, cultural value and competence are also measured. Despite accounting for only $5 \%$ to $10 \%$ each, lower scores on cultural value and competence will greatly affect the general assessment.

Firm E evaluates the progress of the annual performance targets two times in a yearat the mid-year and the end of the year. The evaluations are mainly carried out by each employee's immediate superior. Although the employee first conducts a self-evaluation, the firm emphasizes that the self-evaluation is only a reference that does not count toward the final result evaluated by management. A score of 4 or 5 in the performance evaluation puts the employee in danger of that year's eliminations. The individual laborer represents the basic unit for evaluation. In virtual team cooperation, differences in performance targets unavoidably lead to conflicts in individuals' interests. In this regard, internet laborers also exhibit the "atomization" described by Braverman.

When setting KPIs, both vertical disintegration and horizontal coordination (crossteam, cross-department cooperation) should be considered. The actual practice mechanism, however, only ensures the effectiveness of vertical disintegration. For example, KPs that have a larger influence on the superior's target completion or direct and significant effects on employees often carry a heavier weight. Performance evaluation is mainly conducted by the immediate superior. Therefore, horizontal coordination has little influence in practice at the evaluation stage as there is no actual evaluative indicator for it. Horizontal coordination is partly evaluated with cultural value items. However, the system and method of evaluation are still bureaucracybased. Bureaucratic characteristics are still the core of performance evaluation.

The two institutions of Firm E exhibit a seemingly contradictory but rational organizational structure. The contradiction is between the cultural foundation of virtual teamsthe engineer culture of equality, autonomy, and cooperation-and the bureaucratic performance evaluation, which indicates an individual orientation and hierarchical characteristics. On the surface, the two aspects demonstrate an unsolvable dichotomy. It is rational, however, because the engineer culture shows both the firm's acceptance of and compromise with the internet culture as well as its emphasis and elevation of internet technology to the mainstream to promote innovation and progress in production. Bureaucratic performance evaluation is a managerial control method that capital uses to address uncertainty in labor transition and to secure surplus value. From this perspective, the two aspects converge in the goal of promoting the production of surplus value. 
However, contradictions in institutional arrangements will necessarily influence production. In the following, this article will further discuss the consequences of such contradictions.

\section{Differentiation of virtual teams in the labor process}

Similar to many other Chinese internet companies, Firm E drives production mainly through projects. Here, a "project" refers to "utilize[s] a specific organizational structure to complete a one-time task with [a] clear expected target (a unique product or service), under constraints of time and resource" ( $\mathrm{Qu}$ 2012). In the internet labor process, the "specific organizational structure" is the project team, which includes groups such as RD (software developers), PM (product managers), and QA (quality assurance). In Firm E, specifically, the main format is the virtual team.

"Virtual team" is defined here slightly differently from the common definition in the business management scholarship. ${ }^{5}$ Members of a virtual team come from a variety of actual departments. In sharp contrast with the bureaucratic hierarchy between managers and the managed in real teams, virtual teams consist of equal and cooperative relationships. Otherwise, the daily evaluation of laborers is still the responsibility of the leaders of real teams. The framework of the virtual team is rooted in project management ideas developed since the mid-twentieth century in the business sector (Davis et al. 2010). In the project management structure, projects have a singular, piecemeal, life-course model (Yue 2012) and provide cross-department solutions (Cheng et al. 2004). In this sense, virtual teams in Firm E are managed in the same way as normal projects. The difference lies in the virtual teams' simultaneous "crossing" of organizational boundaries and elimination of bureaucratic power relations. Each virtual team member cooperates on mostly equal ground, while their position and power in their corresponding real team have little effect. Project managers in Firm E, who are centrally responsible for managing and coordinating in project management, become rank-and-file workers who only coordinate but do not manage in the virtual team working process. In this sense, virtual teams are more than the "cross-department solution" in conventional project management. They are a unique mode of operation that dissolves organizational and bureaucratic power relations. As such, the virtual team is a method of work, while the real team is a management method. The two institutions combine to form a "horizontally virtual and vertically real" organizational structure.

The organization constructs virtual teams for innovation. Through this method, capital not only provides an organizational basis to promote creativity but also constructs a virtual commonwealth similar to the scholar community. At the same time, the bureaucratic institution of performance management remains the real organizational structure and traditional managerial control method. When these two methods encounter each other in the same organization, what kind of labor process will emerge? How will the clash among individualism, hierarchical culture, internet culture, and engineer culture influence the labor process? How should laborers and capital react to such conflicts? We discuss these issues with stories of the labor process.

${ }^{5}$ The management scholarship defines "virtual teams" with an emphasis on cross-time and cross-space cooperation enabled by IT technology (Yan 2001). 
Projects in Firm E last from 2 weeks to a year, with most of them lasting for 3 months. A common project involves all eight occupations. From the proposal of needs to the launch of the product, a project is generally divided into six stages: proposing the need, establishing the project, production, launching the product, operating the product, and updating. In the first stage, the necessity and viability of the proposed product are discussed. In the project establishment stage, evaluative meetings are called for to gather detailed suggestions on the product's viability from each real team's representative. When production begins, technical experts give specific design plans and schedules based on which the product is gradually conceived and produced. The finished product is then launched-that is, integrated into the firm's general product structure and opened to users. This is the key time point that determines the success or failure of the project. Usually, this time point marks the end of the project's life course. Subsequent management, operations, and updates are the responsibility of specialized departments outside of the virtual team.

On paper, the above-mentioned project workflow is concretely, smoothly, and thoroughly designed. However, conflicts and uncertainties prevail when it is put into practice in the actual field of labor. Due to space limitations, in this article, we discuss only the scheduling stage.

Scheduling is a key stage after a project is established. The project manager (PM) works with the engineers (RD) on a concrete design for the product, based on which the $\mathrm{RD}$ team generates an estimated schedule for the project from start to end. Seemingly simply an objective estimation of future work, scheduling is, in fact, one of the most important leverages of the RD team. After a project is established, a small RD group joins the virtual team. However, the RD group may be involved in multiple projects simultaneously and therefore has priorities among those projects. If the RD group does not agree with a project or does not think it is important, that project will be pushed back into the group's schedule. For the project manager, her project being situated late in the schedule constitutes a huge challenge. The following experience of project manager He Feng is typical:

Most firms are driven by projects. A project is essentially to finish something with limited resources and time... Normally, PM and RD correspond directly with each other. You may not have the necessary resources when you start a project; then, you'd have to find them in the corresponding department to form the virtual team. If I go talk to them, [they might say] they're not willing to do it - or they wouldn't just say they won't do it, but they would say they don't have the resources either. In that case, can I postpone it? If I have to postpone it for two months, our PM wouldn't be able to push for the project at all because of the time cost. So we want to rush and push for things, not drag things on. ${ }^{6}$

As shown here, the project orientation already places huge time pressure on the virtual team's labor process. The life course of the project is the life course of the virtual team and the key time for performance evaluation for each occupation involved. Therefore, it

${ }^{6}$ Interview of He Feng, Project Manager of Firm E, August 23rd, 2012. 
is important to access the necessary teams and resources in a limited amount of time to achieve the final goal of the project.

However, every organization has only limited resources. This is especially the case in the virtual team environment that dissolves administrative ordering. How does the team fight for resources?

In this case, you have to break through. There are several options. The first is just to wait. This is the most passive. Another choice is to ask my supervisor if she could coordinate the resources for me. She would talk to their supervisor. Their supervisor may agree and provide several names for me to talk to. Sometimes those people would still tell me they don't have the resources. They would tell me to go ahead and design the project first, and then they'd see if they have the resources. In this case, normally, the project would drag on for half a year or even longer. It's unlikely that we [would] just give up on the project. I'd have to find another way to get the resources to develop it. There are internal resources and external resources. Some resources for development are outsourced, but that's not encouraged. I would look for internal resources from my own department or other related departments. They have their own products that have already taken shape. I would join their group chat for a product and ask to talk with them about potential cooperation. They would tell their manager. Once I, on my own, talked to four or five people from another department and asked [if I could] cooperate with them. They thought it was a great idea and agreed to work together. ${ }^{\text {? }}$

He Feng finally found some technical personnel to form a virtual team without his supervisor's help and ensured that his project was finished and launched within a limited time. In this process, the supervisor of his real team had very little influence on getting support from other real teams. Clearly, the virtual team significantly affected the bureaucratic authority. From another perspective, this is also a reflection of equality and autonomy in the virtual team. If conventional authority is partly defunct, what is the basis of cooperation now? When asked why the other team would agree to cooperate with him, He Feng offered the following:

This project had a great influence on their department. For example, they had been doing knowledge accumulation at the firm level, which only covers people at the headquarters. If they want to continue accumulating knowledge, they'd have to go deeper or expand wider. How to expand their range? To branches and partners through my channel. So, this is very valuable to them. They can use it to fight for larger discourse and influence. I just recently realized this - all these groups are like organs in your body. Every organ has its own purpose and interest. They all fight with each other for it. ${ }^{8}$

In fact, bureaucratic authority is partly deconstructed in the cross-departmental cooperation of the virtual team. Administrative orders can hardly influence the behavior of

\footnotetext{
${ }^{7}$ Interview of He Feng, Project Manager of Firm E, August 23rd, 2012.

${ }^{8}$ Interview of He Feng, Project Manager of Firm E, August 23rd, 2012.
} 
members of the virtual team. Interest is at the center. Each laborer becomes an independent interest entity under bureaucratic performance management. Because of this subordinating relation, individuals and their real teams become one interest community. To a certain extent, the real team is an independent interest entity in the organization. The cooperation process of the virtual team essentially becomes a game between the real team and individual laborers. Interest becomes one of the most important influential factors in cooperation in the virtual team. Since the performance management system is an important institution that the firm establishes for managerial control, we can infer that the influence of the interest principle on cooperation in the labor process is determined by the organizational structure, while laborers are passive actors for implementation and exercise.

In Firm E, another form of cooperation exists that does not involve direct interest relationships but is based on personal relationships between individual laborers.

The encouragement we PMs give to team members, I would characterize it as lip service. You don't have anything they want, but [you] ask them to work hard to contribute to your project. But your lip service needs to sound genuine to them. You really want them to help you, so you need to put yourself in their shoes. What good does this thing provide for RD? Don't emphasize the benefit for the project. What does it give to $R D$, the person who works overtime for your project? Give him a reason first. Other than that, there's emotion. To be honest, don't wait until you need them to treat them to a dinner or afternoon tea. Rest assured, this is a small world - one cooperation leads to the next. Even if he doesn't have another opportunity to work with you again, people around him may. You need to build this network. ${ }^{9}$

PMs carry that idea through in actual cooperation.

I often treat them to dinners. Landmarks in the project - for example, when we exceed 50,000 views, when our new data package is launched - are times for that. If you put yourself at the position of the project manager, the soul of this project, then [making] these [kinds of gestures] is what you're supposed to do. For my current team, this was necessary for more than half a year. Now everyone has known each other for one or two years. Later, when we exceeded 100,000 views, I offered to buy them lunch. They were like, "Take a break! How much do you earn every month? Save for your family. Don't spend it all on us." See, they care about me now. So, then I proposed to have a little fun together. They would say we can do that in the dining hall, or we can just have ice cream together, things like that. They care about me a lot because we gradually have emotional bonds..$^{10}$

In this kind of cooperation, laborers are often at the same level and from different real teams. Members of the virtual team have no administrative hierarchy or resource or interest conflict between them. Successful cooperation is mainly based on personal relationships between laborers. Unlike personal relationships in everyday life, which are formed on blood or regional basis, personal relationships in virtual teams are intentionally formed by laborers to promote cooperation. From this perspective, these personal

\footnotetext{
${ }^{9}$ Field notes from a training session of the Project Department of Firm E, August 7th, 2012.

${ }^{10}$ Interview of Nan Zheng, Project Manager of Firm E, August 31st, 2012.
} 
relationships are closer to the concept of emotional labor (Hochschild 1983). The purpose for laborers to build personal relationships and bonds is embedded in the labor process, with production at the center.

At the same time, personal relationships in virtual teams implicate identification with and compliance with interest principles. They acknowledge the rationality of individual development and interest, as well as its priority when personal relationships fall into conflict. In fact, this reflects the subordination of the value of personal relationships in cooperation with the interest principle of bureaucratic performance management in the labor process.

It should be noted that the existence of this double dilemma in Firm E causes tremendous changes in the labor characteristics of the operational processes of virtual teams. Work on the virtual team was originally knowledge labor, but because of the necessity to construct personal relationships to promote production, emotional labor becomes an integral part of it. However, most projects in Firm E die due to unsuccessful cooperation.

To summarize, in the labor process of virtual teams, the bureaucratic performance management system still has a major influence. By emphasizing the performance of each laborer, it reveals the interest differentiation and authority relations among individual laborers and real teams, reinforcing the influence of the bureaucracy on virtual teams. Laborers, therefore, exhibit a kind of individualization and atomization similar to that of industrial laborers.

Objectively, virtual teams pose a real challenge to the bureaucracy by freeing part of the labor process from the control of administrative orders. It provides the possibility for equal, democratic cooperation and the generation of laborer agency. The emotional labor of constructing personal relationships is an important indicator of this aspect. However, can this kind of personal relationship counteract the atomization resulting from the bureaucracy? Can it fuel the formation of a virtual community? First, the personal relationship built through emotional labor is essentially aimed at pushing production and cooperation. This instrumental-rational consideration gives such personal relationships an inherent instrumentality, which is not ideal for forming virtual communities. Second, personal relationships acknowledge the rationality and superiority of the interest principle. They, therefore, take a backseat in production and cooperation. Their influence is complementary and subordinated. As such, personal relationships also demonstrate labor agency, and they can hardly pose a critical challenge to the bureaucracy.

\section{Conclusion and discussion}

\section{A doubly contradictory institutional arrangement}

The previous discussion about the labor process in virtual teams demonstrates the production process and organizational methods in internet firms. The construction of virtual teams has a similar structure and rules as the scholarly community that gave rise to internet technology. The engineer culture promoted by Firm $\mathrm{E}$ also provides cultural support to the operation of virtual teams. Therefore, the virtual team mode of production in Firm E can be seen as an effort to construct a virtual community among laborers. It essentially constitutes a complement to the bureaucracy, which lacks adaptability and flexibility. It is both the foundation of innovation and the compromise the firm makes to technology and its culture. 
From a deeper perspective, however, why would the firm make such a self-contradictory institutional arrangement? To answer this question, we must return to Marx to investigate the surplus value of internet labor. Marx argues that the uncertainty in the industrial labor process directly gives rise to managerial control strategies. The uncertainty here refers to the transition of workers' labor power into actual labor in the production process. In the knowledge production process in the internet industry, the uncertainty problem remains, but the conditions for its occurrence have changed. In the era of globalization, continuous innovation is the lifeline of internet firms. A free and equal working culture and environment are widely recognized as the foundation for innovation to happen. In other words, compared to industrial production, internet companies face a more complex environment as they must deal with uncertainty issues. On the one hand, managerial control is needed to solve the issue and ensure the production of surplus value. On the other hand, autonomy and equality are needed to transform laborers' knowledge and skill into innovation. The two aspects are contradictory to some extent. This is a key problem for which internet companies must find a solution to organize the production process. Internet companies have achieved a certain level of acceptance of technology culture to deal with this problem. The doubly contradictory virtual team labor process is an institutional compromise with technology culture and general managerial control. Under such an institution, internet companies have rapidly and efficiently developed.

\section{Reflection and reconstruction: the labor process theory in the network society}

Returning to labor process theory, the doubly contradictory virtual team labor process poses a theoretical challenge to the conventional idea of the relationship between technology and ideology. Compared to industrial production, internet technology has two distinctive characteristics. First, the skill becomes part of the laborer. Industrial laborers can be "deskilled." This is not the case for internet laborers, of whom internet technology is an integral part. The inseparability of the two means that the firm cannot intervene in the labor process through traditional managerial control methods. It must construct a new management model for production. Second, technology acquires a cultural dimension. Technology culture is a critical feature for both the birth of the internet and its exercise in the labor field. Laborers have cultural capital. Firms construct organizational culture around it. The technology culture, therefore, constitutes an important source of ideology in the labor process. Although the firm's reconstruction of the engineer culture "alienates" it to a certain extent (Liang 2015), from a theoretical perspective, ideology in the labor process is no longer a one-sided construction by capital. The autonomy and agency of laborers are also demonstrated in terms of ideology. ${ }^{11}$

From the practice of the labor field, we can see that managerial control remains the main aspect of the labor process. Bureaucratic management and performance evaluation

\footnotetext{
${ }^{11}$ In other studies on knowledge labor, scholars have mentioned the autonomy and agency of professional laborers (Ma 2013). In comparison, a distinctive feature of the ideological autonomy and agency of internet laborers is that they are obtained under capital's strict control over technology and labor. Such control includes macrolevel control through industrial investment and development, and microlevel influence on the organization of the firm. This aspect is unique to the internet industry compared to other highly professionalized knowledge labor. The meaning of such ideological autonomy and agency becomes clearer as we compare industrial production and internet labor from a perspective closely related to capital.
} 
construct real teams and individual interests, divide virtual teams, and subordinate the personal relationships formed between laborers. The same goal is achieved in the ideological sphere, reconstructing the engineer culture into a corporate culture that is "alienated" to fit the characteristics of the firm's production. From this perspective, technology and culture make laborer agency possible and incentivize the firm to adjust the production process. However, the degree to which laborers can achieve autonomy relies on the interaction between labor and capital and practical production in a particular field.

For theory development, the conventional understanding in which technology and ideology have a parallel and interactive relationship should be revised. Technology transformations, especially technology culture, give laborers autonomy in both the content and the constructive mechanism of ideology. Technology and ideology integrate to a certain extent during the labor process of internet companies. The ideological part of the labor process comes from the technology itself. Discussion from any single perspective will be inadequate for a comprehensive understanding of such a labor process. As such, further theory development must review and reflect the existing research scheme. The relationship between technology and ideology must be examined to better understand, and based on that we can analyse the effect of changes in new technology on labor-concerning phenomena, issues, and distinctive characteristics.

Although internet firms have diverse modes of organization and production, this study posits that the technology transformation perspective remains the most critical path to follow in the analytic process. The integration of technological transformation into the analytical framework of labor process theory will benefit o point out the differences between labor studies on traditional industries and the information technology industry.

Abbreviations

ARPANET: Advanced Research Project Agency Net; BBS: Bulletin Board System; CEO: Chief Executive Officer; PM: Product manager; RD: Research and development engineer; VP: Vice President; KPs: Key performance; KPI: Key performance indicator; QA: Quality assurance.

\section{Acknowledgements}

This paper is developed based on the author's doctoral dissertation. It was presented in the 2015 Annual Meeting of the Chinese Sociological Association Labor Sociology Section. The author sincerely thanks Xin Tong and Hanlin Li for their help in the writing and revision of this paper. The author also thanks Dongling Ma and other peers for their encouragement, as well as the anonymous reviewers for their constructive suggestions. The author takes full responsibility for this paper.

Authors' contributions

All authors read and approved the final manuscript.

Funding

N/A.

Availability of data and materials

This study is based on my interviews with Firm E' employees.

Declaration

Competing interests

The authors declare that they have no competing interests.

Received: 16 June 2021 Accepted: 11 November 2021

Published online: 01 December 2021 
Braverman, Harry. 1978. Labor and Monopoly Capital: The Degradation of Work in the Twentieth Century. Trans. Sheng Fang, Jijun Zhu, Yixuan Wu, Weihe Chen, and Qipin Zhang. Beijing: Commercial Press.

Burawoy, Micheal. 2005. Manufacturing Consent: Changes in the Labor Process Under Monopoly Capitalism. Trans. Zonghong

Lin, Fengyi Zhang, Lixuan Zheng, Xinru Shen, Dingjie Wang, Wenren Zhou, and Xisheng Wei. Taipei: Socio Publishing Co. Ltd.

Castells, Manuel. 2007. The Internet Galaxy: Reflections on the Internet, Business, and Society. Trans. Bo Zheng and Wei Wu. Beijing: Social Sciences Literature Press.

Castells, Manuel. 2009. Informationalism, Networks, and the Network Society: A Theoretical Blueprint. In Manuel Castell eds. The Network Society: A Cross-Cultural Perspective. Trans. Kai Zhou. Beijing: Social Sciences Literature Press.

Cheng, Tiexin, Jidong Huo, and Yuanzhang Liu. 2004. A Review for the Evolution of Project Management. Management Review 16 (2): 58-62.

Liang, Meng. 2015. Reconstruction of Cultural Capital in Knolwedge Labor: A Case Study of Internet Firm E. Journal of Social Development (1).

Ma, Dongling. 2013. Professional Care: A Qualitative Study on Nursing Work. Ph.D. dissertation, Department of Sociology, Peking University.

Marx, Karl. 2004. Capital Volume I. Trans. The Central Compilation and Translation Bureau. Beijing: Commercial Press.

Mosco, Vincent, Jin Cao, and Baoda Yang. Social Theory and Knowledge Workers in the Information Society. Journalism Quarterly (1).

Qiu, Linchuan. 2009. Labor Issues in the Emerging Network Society. Open Times (12).

Qu, Jingdong. 2012. Project System: A New System of State Governance. Social Sciences in China (5).

Wang, Jianhua. 2011. Internet Mobilization and Collective Struggle of Factory Workers. Open Times (11).

Wen, Xiang, and Xiao Zhou. 2007. Western Theory of Labor Process and the Chinese Experience: A Critical Review. Social Sciences in China (3).

Yan, Shimei. 2001. Virtual Teams and Their Management. Foreign Economics and Management (5).

You, Zhenglin. 2006. Managerial Control and Worker Resistance: A Review of Literature on Capitalist Labor Process. Sociological Studies (4).

Yue, Haisheng. 2012. Developmental Trends of Project Management and Countermeasures. New Technology and New Products of China (1).

\section{Publisher's Note}

Springer Nature remains neutral with regard to jurisdictional claims in published maps and institutional affiliations.

\section{Submit your manuscript to a SpringerOpen ${ }^{\odot}$ journal and benefit from:}

- Convenient online submission

- Rigorous peer review

- Open access: articles freely available online

- High visibility within the field

- Retaining the copyright to your article

Submit your next manuscript at $\boldsymbol{\Delta}$ springeropen.com 